\title{
Communications and Information Technology for Persons with Disabilities - The Canadian National Strategy as an Example
}

\author{
Mary Frances Laughton \\ Industry Canada \\ Ottawa, Ontario, K2H 8S2, Canada
}

\begin{abstract}
Persons with disabilities have major reasons for use of adaptive systems. These individuals are often handicapped by not having access to traditional forms of communication and information. An individual who is blind cannot read print information. A person who is deaf cannot usually obtain information directly via telephone. An individual with a speech impairment may have the same problem with respect to telephone contact. A person who is in a wheelchair may not have physical access to buildings which house information services and, even if they can get in, their physical limitations may prevent them from using those services without extraordinary assistance. Industry Canada has been involved for a number of years in the development of assistive devices in partnership with a number of Canadian organizations. The search for a global market is always there.
\end{abstract}

\section{Introduction}

This paper will report on a series of Industry Canada (a Federal Government department) supported projects to develop communications and information technology (C\&IT) tools, systems and services which assist persons with disabilities to communicate with each other and with persons without disabilities. The programme described is called "Communications for Persons with Disabilities."

The right to communicate has been regarded by many as a fundamental right. However, many Canadians are denied access to the normal communications channels due to a disability. The visually impaired cannot fully enjoy television and books without special aids. They need special devices to be able to be fully functional in the workplace. The hearing impaired require captioning to enjoy movies and television. They require special devices to use the telephone. Speech impaired persons have need for augmentative communications tools and languages. Mobility impaired have need for special interfaces to use computers and other communications devices.

The ability to communicate without the need for an intermediary increases independence and will reduce attendant care costs significantly. The ability to easily communicate increases one's self esteem greatly. 
Canada has always been a world leader in communications. The telephone was invented here and Canada maintains one of the best phone systems in the world with over $97 \%$ of households having at least one telephone. Canada had the first domestic communications satellite. Our packet switched network was one of the first. Our radio and television broadcasts are world renowned.

The overall aim of the Canadian strategy is to implement tangible steps that will address the communications needs of Canadians with disabilities in a coherent and pragmatic fashion through cooperation amongst all levels of Government and the private sector.

All Industry Canada activities relating to persons with disabilities are done within the context of the Canadian National Strategy on the Integration of Persons with Disabilities. This is a cross-Government programme designed to increase the integration of persons with disabilities into Canadian society. Communications and information technologies are but one of many tools required but they are a fundamental need!

Industry Canada has been active in the development and implementation of technology and services that improve communications for Canadians with disabilities, but there is much more to do. Many communications problems can only be addressed by fully researching the problem and then developing devices, programmes, tools or whatever is required to meet the needs. There are many activities that go on in Government and other laboratories that could be used to improve communications. Financial assistance needs to be provided to share some of the risk for field testing, trial and other demonstrations. There are a number of private sector and government organizations who are trying to address the C\&IT needs of persons with disabilities.

Of great benefit is the ability to get a "critical mass" of devices or systems to be tested to provide the feedback required and to provide the momentum required for full implementation.

In this paper, I will describe the projects ongoing and planned. The partnership aspect with the private sector will be highlighted. The possibility of global markets for these developments will be examined.

In 1993, we completed the first Canadian needs study ${ }^{1}$ for C\&IT products, systems and services. It also provided a directory of R\&D underway in Canada and elsewhere, a listing of conferences and a bibliography. It has been widely distributed and is being used as an awareness raising tool for the programme and as a textbook for special university courses. It is now being revised. It is our hope to undertake the R\&D to meet many of the needs identified.

$15.3 \%$ of Canadians (4.5 million people) indicated in the 1991 Census that they have some form of disability. Figure 1 shows the breakdown by type of disability. 


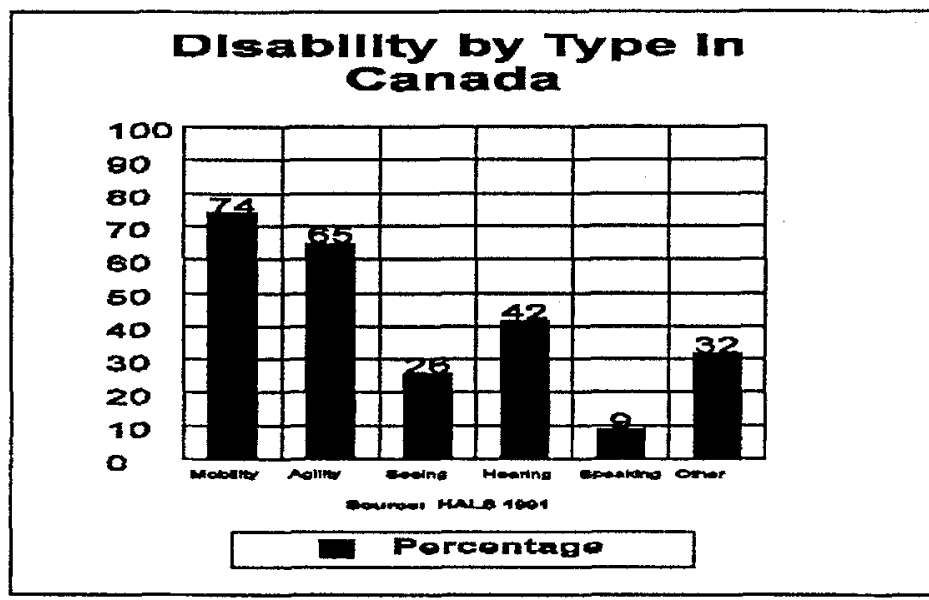

Mobility 74

Agility 65

Seeing 26

Hearing 42

Speaking 9

Other 32

Figure 1

3

Standards

Industry Canada has the responsibility for the development and implementation of C\&IT standards. Computer technology has provided persons with disabilities with a means by which they can be more independent in their quest for information. Within computer-mediated communications systems, it is not just barriers between the individual and the information they seek which are broken down; it is also the barriers between people. A person who is deaf may talk to a person who is blind; a person who is both deaf and blind may communicate with the world. An able-bodied individual may discuss issues with people with disabilities without knowing the state of the other individual. The only way that this communication can be ensured is with the adherence to recognized standards. The TTY/TDD telephone for the deaf is first and foremost a standard. The Blissphone project (described later) revolved around the development of an international standard.

4

Process

Each project undertaken is reviewed against several criteria. There is an Advisory Committee of experts which provides guidance to the programme.

1. Is there a user need? The user community is involved in the design of each project and, indeed, is in most cases a partner in the project.

2. Does the project deal with developed or emerging standands? The question of C\&IT standards is a central point of each project. 
3. Will the systems developed continue after Government involvement? It is important in any project but especially one in support of people with disabilities that expectations not be created that will not be met. This is the case in each of the described projects.

We produce a report that can assist others in understanding the lessons learned, both positive and negative, in the development process. These reports are available in alternate formats and, by the time this paper will be given, will be available over the Internet.

\section{$5 \quad$ Project Descriptions}

\subsection{Grocery Product Reader}

Needing only simple tools, a computer, a speech synthesizer, a relational database and a standard, the UPC (universal product code), in partnership with the Canadian National Institute for the Blind, a product has been developed to allow people with visual disability to identify their grocery products using a scanner. This product, called ScanTell (a project of Compusult in St. John's, Newfoundland) is now being readied for market and other uses of the technology are being investigated in work situations. It is shown schematically in Figure 2 .

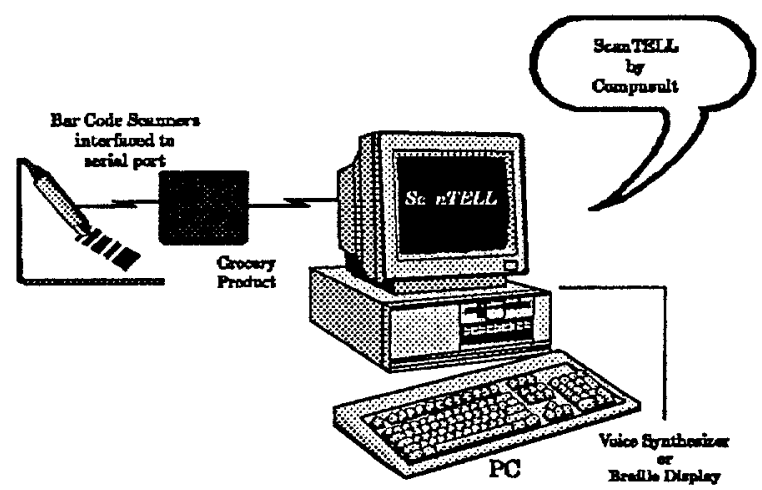

Figure 2 


\subsection{Newspapers for the Print-Handicapped}

It is possible to send a newspaper electronically using a datacasting channel. This did not seem to be an interesting application since the paper copies which we all love so dearly are relatively cheap to produce and people do not generally like to read from a computer screen. However, the transmission of the newspaper via datacasting to the print-handicapped may be ideal. The newspaper is received and stored in a PC. The consumer can then use the numeric keypad to choose which stories should be read to him/her by a voice synthesizer or an alternative braille output device. This enables people with a print handicap to have all the news stories the same as somebody fully sighted.

Since there are 500,000 visually impaired persons in Canada and many other persons with disabilities which make it difficult for them to read a newspaper, a datacasting service is required to distribute the text of the newspaper in order that many of them can all be served.

Similar projects are underway in Sweden, Britain and Japan. In conjunction with the Canadian National Institute for the Blind, an international network of Newspapers for the Blind will be instituted so that information gained in each of the projects will benefit from other's work. A schematic of the system is shown in Figure 3.

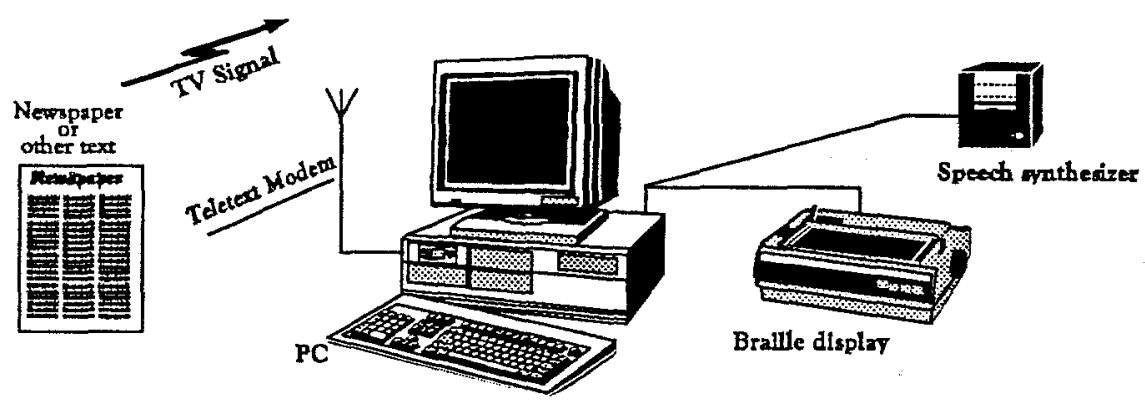

Figure 3

\footnotetext{
${ }^{I}$ Datacasting is the use of electronic means to make data broadly available to geographically dispersed sites at the same time. In the case of this project, the method of distribution is teletext which is the use of the vertical blanking interval (VBI) of a television channel.
} 


\subsection{Descriptive Captioning}

Descriptive captioning is a means by which the visually impaired can enjoy a television broadcast in the same way the sighted can. The system in use in the United States uses the stereo channel of a TV broadcast to distribute a narrative of the scenes on the screen between the dialogue on-screen.

The Canadian project, in partnership with programme developers, broadcasters and cable companies, is to examine other mechanisms than stereo broadcasting by which the description can be distributed. This includes looking at the use of sub-carriers on the FM sound channel and VBI of the TV broadcasts. Some software will need to be developed to properly synchronize the description and dialogue of the described shows.

Once standards are developed for descriptive video, Canadian broadcasts will be able to be made available across the world and a global network of shared shows will make the lives of the visually impaired more pleasant.

\subsection{Home Automation}

Home automation systems play a major role in facilitating environments which provide significant independence in many areas of everyday life activities. For instance, these home control systems will allow seniors and persons with disabilities to have integrated control of items such as lights, appliances, TV, VCR, security systems, entry ways, intercoms, telephone and thermostats. Consequently, these automated homes significantly reduce the dependence of these persons on others and, hence, facilitate a substantial increase in the quality of life of these individuals. The desire to obtain or maintain a given level of independence is extremely powerful and, therefore, persons who could potentially increase and/or maintain their independence will vigorously pursue viable avenues that will facilitate their ability to take advantage of automated living environments.

Until recently, most home control systems have been developed in the domain of hobbyists who are interested in controlling various aspects of their home for reasons of fuel efficiency, security or novelty. The major problem with these systems is that the degree of manual dexterity required for their operation made them inaccessible for the use by persons with limited physical movement. For example, most systems used input devices such as keyboards or touch-screens.

The Neil Squire Foundation has developed the Remote Gateway, primarily using simple commercially available components. The device includes a portable remote voice/viden terminal mounted on an electric wheelchair, a very functional and efficient method of remote control.

The Gateway presents menu oriented home control information on a compact video screen contained in a portable remote unit. The user uses voice commands to actuate the various control functions and is able to carry out two-way conversations either on the telephone or 
over an intercom system. In addition, the user can view video information from one or more security cameras. The remote unit communicates to a base unit through a wireless link. The base unit provides the support for the user interface, the voice recognition and the portal into the system.

The fundamental requirements for this product were: user-friendly, voice actuated, visual feedback, portable, highly robust wireless link. Continuing technological advances are increasing the extent to which people can manage their living environments. Recent advances in the automation industry are opening up new applications that were previously not feasible or too expensive. Industry activity suggests that one of the first areas of growth in this market will be for the special needs population. Providing seniors and persons with disabilities greater opportunities to lead autonomous lifestyles has obvious social and economic benefits.

\subsection{Jouse}

The jouse is a mouth activated mouse emulator that is now being beta-tested by those quadriplegics who have a need for it. This is one of a suite of adaptive switches developed under the programme. It is shown in Figure 4.

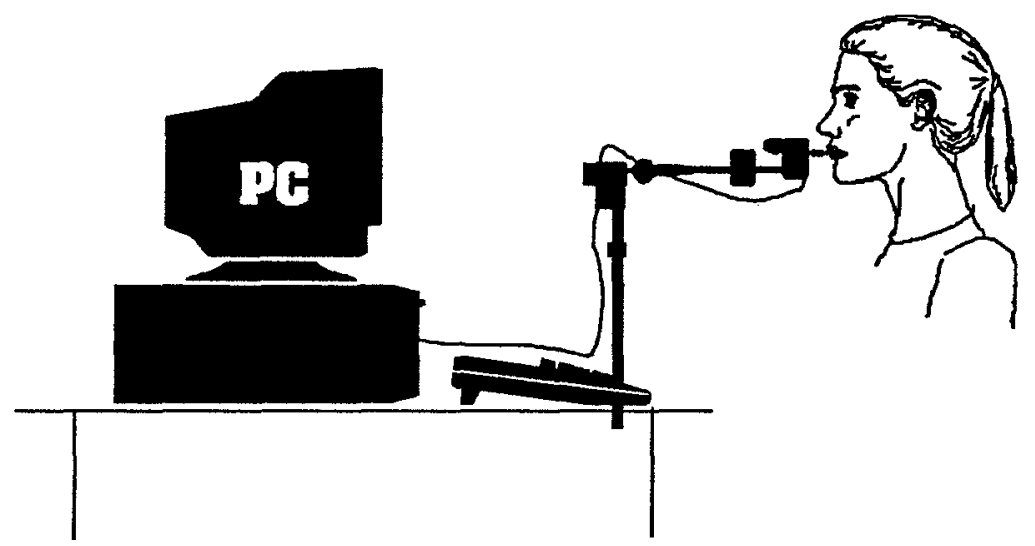

Figure 4

\subsection{Bliss}

Industry Canada was a partner in developing the BLISSPHONE, a telephone for the speech impaired. There are over 30,000 people in Canada who cannot speak for reasons other than hearing impairment. The causes of their impairment include cerebral palsy, muscular dystrophy, stroke and other neuro-muscular diseases. Currently there are more than 3500 Bliss symbols in use. The symbols are based on a language created by Charles Bliss ${ }^{2}$. The 
symbols were left in perpetuity to the Bliss Communications Institute which is in Toronto.

We aimed to make electronic communication using Blissymbols available to the largest number who could benefit from their use. Messages can be sent and read using a specially developed programme. An e-mail service is available and there is the possibility of real time "discussion". The aim was to ensure that the coding scheme is recognized internationally and that is now the case ${ }^{3}$.

Since Bliss is used in over 35 countries worldwide, the global aspects of this project are always in mind.

6 Conclusions

For many of us, disability is a word that conjures up a picture of a person in a wheelchair. But we don't really stop to think what it means to the person in the chair.

It's not just the issue of putting in wider doors and ramps to make buildings wheelchair accessible. It goes a lot deeper. Disability can mean that you have trouble feeding yourself or that you may have difficulty in making a controlled movement of the hand, foot or head in order to press a simple switch. It can also mean having ideas in your mind that you are unable to express because you can't easily communicate.

We are all disabled to some extent as disability is a continuum. All of us will become disabled simply as a result of the aging process. There is a good chance, therefore, that all of us will at some point need an assistive device.

We hope the Blissphone, the Jouse, the automated house, descriptive captioning, electronic newspapers and many other technologies will give Canadians with disabilities a direct line to the rest of the world.

\section{$7 \quad$ References}

1. Communications and Information Technologies and Persons with Disabilities, Industry Canada, 1993.

2. Blissymbols for Use, Blissymbolics Communication Institute, 1980

3. ISO 8875,1993 